\title{
Oxygen Saturation of Hemoglobin in Healthy Children of 2- 14 Years at High Altitude in Nepal
}

\author{
Shrestha $S,{ }^{1}$ Shrestha $S,{ }^{2}$ Shrestha $L,{ }^{3}$ Bhandary N ${ }^{4}$
}

${ }^{1}$ Department of Paediarics, Patan Hospital, Patan Academy of Health Sciences

${ }^{2}$ Department of Paediatric Ophthalmology, Nepal Eye Hospital, Kathmandu, Nepal

${ }^{3}$ Paediatric Research Unit, Patan hospital, Patan Academy of Health Sciences

${ }^{4}$ Department of Community Health sciences, Patan Academy of Health Sciences

\section{Corresponding Author}

Shrijana Shrestha

Department of Paediarics, Patan Hospital,

Patan Academy of Health Sciencesl

Email: shri_rishi@hotmail.com

\section{Citation}

Shrestha S, Shrestha S, Shrestha L, Bhandari N. Oxygen Saturation of Hemoglobin in Healthy Children of 2- 14 Years at High Altitude in Nepal. Kathmandu Univ Med J 2012;37(1):40-3.

\begin{abstract}
Background

Individuals residing at higher altitude may have oxygen saturation of hemoglobin different to those living at lower altitude.
\end{abstract}

\section{Objectives}

To find out the baseline value of SpO2 in healthy Nepali children (2-14 years) living permanently at high altitude using pulse oximeter and also to study the relation of $\mathrm{SpO} 2$ with age, sex and ethnicity

\section{Methods}

A descriptive observational study was conducted at 4 different altitudes ranging from 2700 to $3800 \mathrm{~m}$ in Mustang district. The mean pulse oximery values at different altitudes were calculated and compared.

\section{Results}

One hundred six children were enrolled with the median age of 10 years. The mean SpO2 value of children permanently residing at altitude $2700 \mathrm{~m}$ was $95.18 \%$, at $2800 \mathrm{~m}$ was $94.82 \%$, at $3550 \mathrm{~m}$ was $94.1 \%$ and $3800 \mathrm{~m}$ was $93.1 \%$. The difference in the $\mathrm{SpO} 2$ values at different altitude was statistically significant. No sex or age wise differences were noted on the mean $\mathrm{SpO} 2$ values in the study group.

\section{Conclusions}

The mean $\mathrm{SpO} 2$ values were higher than several other studies done in the altitude above $\mathbf{2 5 0 0}$ meters. Enrollment of older children and the different ethnic background could be the contributing factors for the differences.

\section{KEY WORDS}

children, high altitude, Nepal, pulse oximetry

\section{INTRODUCTION}

High altitude environment is characterized by hypobaric hypoxia and low barometric pressure. At high altitudes normal oxygen levels are lower than at sea levels and hence individuals may have their normal oxygen tension and oxygen saturation of hemoglobin different to those living at lower altitude. Pulse oximetry is one of the commonly used tools for assessing the oxygen saturation of hemoglobin and availability and use of this simple, noninvasive tool is now increasing in the health facilities of developing countries. Pulse oximetry has been suggested as a fifth vital sign in paediatrics as it may result in significant changes in clinical decision making. ${ }^{1}$
There are only a few published studies regarding the pulse oximetry reference values in paediatric populations permanently residing at high altitude. A systematic review to define altitude specific hypoxaemia, published in the Archives of Diseases in Childhood has concluded that the lower values of oxygen saturation can be considered appropriate to indicate the need for supplemental oxygen in children at higher altitude in the setting of limited oxygen supplies at the health facility. ${ }^{2}$ However, hypoxaemia may be a single better predictor of pneumonia in high altitude settings than clinical signs.,4 Oxygen supplementation guided by pulse oximetry findings could be life saving in acute lower respiratory tract infections in children at high altitude and optimal thresholds for initiation and 
discontinuation of oxygen supplementation warrants further research. ${ }^{5}$

So far there has been no known/ published study on pulse oximetry reference values for healthy Nepali children living at high altitudes.The objective of the present study is to find the baseline value of oxygen saturation of hemoglobin in healthy Nepali children living permanently at high altitude using pulse oximetry, and to compare these values between different ethnic groups.

\section{METHODS}

A descriptive observational study was carried out at four different altitudes in Mustang district of Nepal: Jomsom (2700 m), Kagbeni (2800 m), Jharkot (3550m) and Ranipauwa $(3800 \mathrm{~m})$. Mustang district lies in the mid western developmental region of Nepal. It has a population of 14,981 and the most common ethnic groups residing in the district are Gurung and Thakali (2001 census). ${ }^{6}$

Healthy Children of either sex, aged two years to 14 years, residing permanently at the given altitudes were enrolled. Children suffering from chronic diseases, congenital heart disease, acute respiratory diseases, cardiovascular compromise and children who have had respiratory tract infections one week prior to the study date were excluded. Children living at the study altitudes but born and lived for more than a month at lower altitudes were also excluded.

For all children fulfilling the inclusion criteria, informed verbal consent was taken from the parents/ guardians and pulse oximetry reading checked and documented for each child by the same individual (Principal Investigator). The pulse oximeter used for the purpose was CMS- 50DL (center for Medicare and Medicaid Services, US)). The pulse oximeter was placed on the index finger or the thumb and several readings were taken until a consistent value was displayed and the pulse rate displayed on the pulse oximeter was consistent with radial pulse simultaneously taken manually on the other hand. Before taking the reading it was made sure that the fingers were warm, and the readings were taken indoors avoiding bright source of light.

The mean pulse oximery values for different age groups were then calculated and compared. Independent Sample t-test, Analysis of Variance (ANOVA), Spearman's rank correlation and simple regression analysis were used for analyzing the data.

The study was approved by the Institutional Review Committee of Patan Academy of Health Sciences, Nepal. (Ref. No: 2011.105.SS)

\section{RESULTS}

A total of 270 children were examined and 106 (47 boys and 59 girls) of age 10 to 14 yrs (median age 10) of them fulfilling the inclusion criteria were enrolled. Out of 106, 47 were male and 59 female. Most of them were between 10 to 14 years, the median age being 10 years. (Fig 1 ) The highest number of children studied was from Jomsom. The population of children residing at the altitude of over 3000 was very few reducing the study sample at those altitudes accordingly. (Fig 2) Eighty percent of the study children were born at the same altitude where they were residing and $20 \%$ children were born either at similar or higher altitude than they were presently residing. Children born at lower altitude and now residing at the study altitudes were not enrolled in the study with the exception of a three children whose mother went to the cities at lower altitude (Pokhara or Kathmandu) just for delivery and were back to the study altitudes within the first few days of delivery.

Mean pulse oximetry values and $95 \%$ confidence intervals (CI) were calculated. The values were normally distributed with a mean of $94.71 \%$ (SD: 1.46 ) and $95 \% \mathrm{Cl}$ of $94.43 \%$ to $94.99 \%$. The mean pulse oximetry value for children at different altitude decreased as the altitude increased. The mean $\mathrm{SpO} 2$ value of children permanently residing at Jomsom (2700m), Kagbeni (2800m), Jharkot (3550m) and Ranipauwa (3800m) was found as $95.18 \%, 94.82 \%, 94.11 \%$ and $93.11 \%$ respectively. The difference in the spo2 values at different altitude was statistically significant. (Table 1)

Table 1. Mean values (\%) for the oxygen saturation of hemoglobin at different altitudes.

\begin{tabular}{|lllllll|}
\hline $\begin{array}{l}\text { Alti- } \\
\text { tude } \\
\text { (meter) }\end{array}$ & N & Mean & $\begin{array}{l}\text { Std. De- } \\
\text { viation }\end{array}$ & Median & $\begin{array}{l}\text { Mini- } \\
\text { mum }\end{array}$ & $\begin{array}{l}\text { Maxi- } \\
\text { mum }\end{array}$ \\
\hline 2700 & 56 & 95.1250 & 1.32202 & 95.0000 & 91.00 & 98.00 \\
\hline 2800 & 22 & 94.8182 & 1.18065 & 95.0000 & 93.00 & 97.00 \\
\hline 3550 & 19 & 94.8182 & 1.66315 & 94.0000 & 91.00 & 97.00 \\
\hline 3800 & 9 & 93.1111 & 1.16667 & 93.0000 & 91.00 & 95.00 \\
\hline Total & 106 & 94.7075 & 1.46689 & 95.0000 & 91.00 & 98.00 \\
\hline
\end{tabular}

Anova: F-test $=7.283, p$-value $=0.000$

Table 2. Mean values (\%) for oxygen saturation of hemoglobin in different age group.

\begin{tabular}{|lllllll|}
$\begin{array}{l}\text { Age grp } \\
\text { years }\end{array}$ & $\mathbf{N}$ & Mean & $\begin{array}{l}\text { Std. Devia- } \\
\text { tion }\end{array}$ & $\begin{array}{l}\text { Std. } \\
\text { Error }\end{array}$ & $\begin{array}{l}\text { Mini- } \\
\text { mum }\end{array}$ & $\begin{array}{l}\text { Maxi- } \\
\text { mum }\end{array}$ \\
\hline $2-5$ & 14 & 95.00 & 1.797 & .480 & 91 & 97 \\
\hline $5-10$ & 30 & 94.27 & 1.574 & .287 & 91 & 98 \\
\hline $10-14$ & 62 & 94.85 & 1.304 & .166 & 91 & 98 \\
\hline Total & 106 & 94.71 & 1.467 & .142 & 91 & 98 \\
\hline
\end{tabular}

$\mathrm{F}=1.982, \mathrm{p}$-value $=0.143$

No sex or age differences were noted on the mean SpO2 values in the study group. Neither did we observe any difference in the $\mathrm{SpO} 2$ values when compared with the different ethnic groups. The children from the ethnic groups Thakali, Gurung, Lama, Sherpa and Magar who have been residing at high altitude for many generations did not show higher $\mathrm{SpO} 2$ values compared to children of other ethnic groups who had migrated to a higher altitude for 


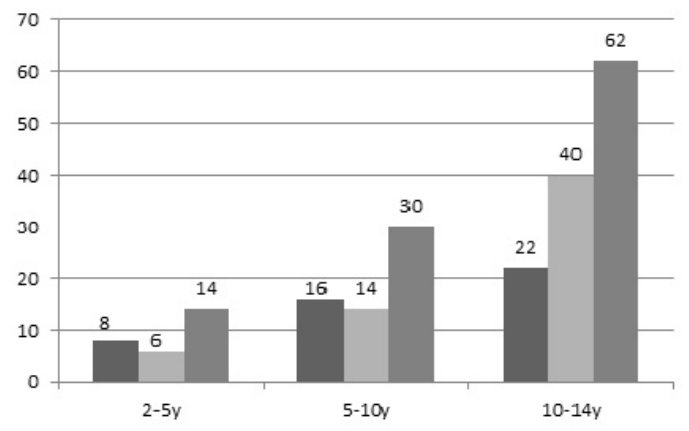

Figure 1. Age wise distribution of the children studied.

the past few generations only.Since one or more variables (age, weight and height) were not normally distributed, non-parametric correlation was used to explore their association with the $\mathrm{SpO} 2$. $\mathrm{SpO} 2$ was not found to be associated strongly and significantly with the recorded age, height and weight as the correlation coefficient were less than $14 \%$ for each one of them and associated $p$-value were all above 5\% using Spearman's Rank Correlation.(Table 3)

Simple Regression analysis with $\mathrm{SpO} 2$ as dependent and altitude as independent variable revealed the statistically different $\mathrm{SpO} 2$ values in altitude of every 850 meters. Simple regression analysis also showed that as the altitude increases by one unit ( 1 meter) the $\mathrm{SpO} 2$ decreases with a factor of -0.001 .Using this regression equation we can predict the $\mathrm{SpO} 2$ values at different altitudes. The predicated data showed that there will be a difference of nearly $6 \%$ in $\mathrm{SpO} 2$ values among children living at the altitude of 1000 and 5000 meters (Table 4).

\section{This shows the regression equation as: \\ Dependent Variable $(\mathrm{SpO} 2)=$ Constant + Altitude in meter \\ Dependent Variable $(\mathrm{SpO} 2)=99.042+-0.001$ \\ This negative sign confirms that as the altitude increases by one unit ( 1 meter) the $\mathrm{SpO} 2$ decreases with a factor of -0.001 .}

Table 3. Rank Correlations among Age, Weight, Height and SpO2.

\begin{tabular}{lllll} 
& Age & Weight & Height & SpO2 \\
\hline Age & 1.000 & $0.927^{* *}$ & $0.909^{* *}$ & $0.110^{\mathrm{NS}}$ \\
Weight & & 1.000 & $0.936^{* *}$ & $0.126^{\mathrm{NS}}$ \\
\hline Height & & & 1.000 & $0.139^{\mathrm{NS}}$ \\
SpO2 & & & & 1.000 \\
\hline
\end{tabular}

$* *$ Significant $\mathrm{P}<0.001, \mathrm{NS}=$ Not Significant $(\mathrm{P}>0.05)$

Table 4. Predicted SpO2 values at different altitude.

\begin{tabular}{|cc|}
\hline Altitude (meters) & SpO2 \\
\hline 1000 & $97.58 \%$ \\
\hline 2000 & $96.12 \%$ \\
\hline 3000 & $94.66 \%$ \\
\hline 4000 & $93.20 \%$ \\
\hline 5000 & $91.74 \%$ \\
\hline
\end{tabular}

\section{DISCUSSION}

The baseline reference values for the pulse oximetry

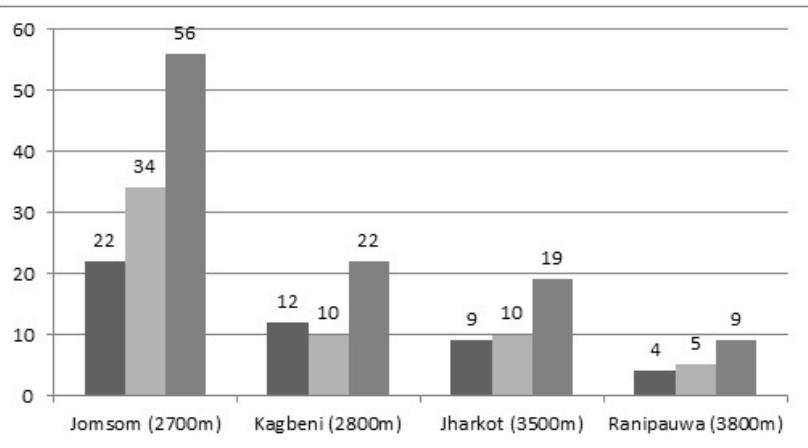

Figure 2. Place wise distribution of the children studied.

readings in children residing at high altitude have been extrapolated based on a few studies done over different parts of the world. There are only a limited number of studies and most studies are done in children under five years of age.

The mean $\mathrm{SpO} 2$ values in several other studies done in the altitude above 2500 meters were lower than the values seen in our study. A study done in 189 children aged 5 to 24 days at Bogota (2640 m above sea level), the mean SpO2 was $93.3 \%(95 \% \mathrm{Cl}$ of $93.0 \%$ to $93.6 \%) .{ }^{7}$ Another study done at the altitude of $2800 \mathrm{~m}$ in 72 children in the age group of 2 days to 22 months in Summit County, USA the mean SpO2 was $91.7 \%$ ( SD: 2.1). ${ }^{8}$ Two other studies at the altitude above 3000 meters ( 3750 and $4018 \mathrm{~m}$ ) in children less than 5 years with sample sizes of 153 and 168 have shown the mean $\mathrm{SpO} 2$ of $88.9 \%$ and $87.8 \%$ respectively. ${ }^{4,9}$

One of the important reasons for higher values of $\mathrm{SpO} 2$ in our study could be that we studied older children (214 years), while all of the above studies included children less than five years. Studies have reported significant differences in $\mathrm{SpO} 2$ between infants and older children, and in this study infants were not included. Younger children were also shown to have a lower mean $\mathrm{SaO} 2$ than older children living at high altitude, which suggests physiological adaptation to high altitude over time. ${ }^{9}$

Other contributing factors could be differences in the genetic background or ethnicity. A study done in lassa has shown that Tibetan infants had higher arterial oxygen saturation at birth and during the first four months of life compared to Han infants. ${ }^{10}$ The majority of the population residing at higher altitude at Mustang district in Nepal are also of Tibetan descent, which could be a contributing factor for our higher values. One another study done in Tibetian population with a big sample size including older children has shown a lower $\mathrm{SpO} 2$ compared to our study. Though population in our study area is mostly of Tibetan descent but is of mixed genetic and ethnic background as the different generations of these people are getting married to local people with a different ethnicity and genetic backgrounds. ${ }^{11}$

Genetic differences among individuals can contribute to individual variation in SaO2. Despite uniform ambient hypoxic stress, Tibetans at given altitude have been found to have wide variation in $\mathrm{SpO} 2 .{ }^{12}$ An adult study done in 
two groups of people: high-altitude controls and highaltitude monks residing at the same altitude of $3600 \mathrm{~m}$ (Ladhak, India) but differing in their daily routines, showed a difference in $\mathrm{SaO} 2$ values measured with a Finger-Pulse Oximeter. The second group (high altitude monks) had 3.08\% higher $\mathrm{SaO} 2(\mathrm{P}<0.001)$ compared to the first, with mean $\mathrm{SaO} 2$ of $91.8 \pm 6.1 \%$ and $89.0 \pm 2.6 \% .{ }^{13}$ The variation in $\mathrm{SaO} 2$ of normal people at high altitude is an evidence of differences in adaptive response to hypobaric hypoxia.10 A study done among a small number (9) of healthy 6-13 year old low land children without prior exposure to high altitude coming to trek in Nepal, has shown that the mean SpO2 values at 3500 meters on day 5 and day 14 were $88.9 \%$ and $91.8 \% .{ }^{14}$ Our study included older children, and only children residing between 2700 to 3000 meters. According to the calculated values from the regression equation from our study $\mathrm{SpO} 2$ at 3500 meters would be between $94.66 \%$ and $93.2 \%$, which is higher than that of the lowland western children. This again highlights the physiological adaptation to high altitude and the difference in the genetic background. No difference in the mean $\mathrm{SpO} 2$ was observed between males and females in the present study and so was observed in few other studies. ${ }^{15,16}$ Sex differences in respiratory capacity occur between adolescence and adulthood. ${ }^{15}$ In another study it was found that adult males had higher $\mathrm{SpO} 2$ values than adult females but did not find any difference in $\mathrm{SpO} 2$ among teenagers. ${ }^{16}$

We tried to study the difference in $\mathrm{SpO} 2$ values in different races/ ethnicity. No difference was noted in children of different ethnic groups. The small sample size for the children belonging to other ethnic groups, who have

\section{REFERENCES}

1. Mower WR, Sachs C, Nicklin EL, Baraff LJ. Pulse oximetry as a fifth Pediatric sign. Pediatrics. 1997;99:681-86.

2. Subhi $R$, Smith $K$, Duke $T$. When should oxygen be given to children at high altitude? A systematic review to define altitude-specific hypoxaemia. Arch. Dis. Child. 2009;94: 6-10.

3. Lozano JM,Steinhoff M, Ruiz JG, Meza ML, Martinez N, Dussan B.Clinical predictors of acute radiological pneumonia and hypoxaemia at high altitude. Arch Dis Child. 1994;71:323-27.

4. Reuland DS, Steinhoff MC, Gilman RH, Bara M,Olivares EG, Jabra A et al. Prevalance and prediction of hypoxaemia in children with respiratory infections in the Peruvian Andes. J Pediatr 1991; 119(6):900-06.

5. Niemeyer S, Mollinedo PA, Huicho L.Child health and living at high altitude.Arch Dis Child. 2009;94:806-11.

6. Statistical Year Book of Nepal 2009, Central Beuro of Statistics, Government of Nepal.

7. Lozano JM, Duque OR, Buitrago T, Behaine S. Pulse oximetry reference values at high altitude. Arch Dis Child. 1992; 67(3): 299-301.

8. Nicholas R, Yaron M, ReevesJ. Oxygen saturation in children living at moderate altitude. J Am Board Fam Pract.1993;6:452-6.

9. Gamponia M J, Babaali F, Yugar F, Gilman RH. Reference value for pulse oxymetry at high altitude. Arch Dis Child.1998;78:461.

10. Niemeyer S, Yang P, Shanmina, Drolkar, Zhuang J, et.al. Arterial oxygen saturation in Tibetan and Han infants born in Lhasa, Tibet. N Engl J Med 1995: 333 (19):1248-52. migrated to higher altitudes for the past few generations only, could be the reason for not finding the difference in $\mathrm{SpO} 2$ between the children of different ancestry. The number of children enrolled at higher altitudes $(>3000 \mathrm{~m})$ was very small as the under 14 population in those places were much less. The number of children of non native ethnic groups who have migrated to higher altitudes for the past few generations only was also too small to confidently study any differences.

\section{CONCLUSION}

The mean $\mathrm{SpO} 2$ values in the present study were higher than several other studies done in the altitude above 2500 meters. Enrollment of older children and the different ethnic background could be the contributing factors for the differences.

However, as this is a very small study with small sample size further research in children with different ethnic groups and different genetic backgrounds, residing permanently at similar altitudes are needed to clarify the issues. This is a preliminary pilot study; the predicted $\mathrm{SpO} 2$ values using the regression equation can be verified in a larger study including children from other altitudes.

\section{ACKNOWLEDGEMENT}

We would like to acknowledge the local volunteers and Professional Support Service Nepal (PSSN) in helping the logistics of the study. We also like to acknowledge Dr Steve Thorson, MD, Consultant Paediatrician, Paediatric Research unit, Patan Academy of Health Sciences for reviewing the paper.

11. Beall CM.Oxygen saturation increases during childhood and decreases during adulthood among high altitude native Tibetans residing at 3800-4200 m. High Altitude Medicine Biology 2000;1(1):25-32.

12. Beall CM, Song K, Elston RC, Goldstein MC. Higher offspring survival among Tibetan women with high oxygen saturation genotypes residing at $4000 \mathrm{~m}$. PNAS 2004;101(39):14300-304.

13. Qadar Pasha M A, Kocherlakota K S, Khan A P, Norboo T, Grover S K, Baig M A, et.al. Arterial oxygen saturation underhypoxic environment of high-altitude associates with routine physical activities of natives. Current Science.2003;85(4):502-6.

14. Scrase E, Laverty A, Gavlak J CD, Sonnappa S, Denny ZH, Levet D ZH et.al. The young Everest study: Effects of hypoxia at high altitude on cardiorespiratory function and general well being in healthy children. Arch. Dis. Child. published online 23 Apr2009; doi:10.1136/ adc.2008.150516.

15. Huicho L,Pawson IG, Lon-velarede F, Rivera-Ch M, Pacheco A,Muro M et.al. Oxygen saturation and heart rate in Healthy school children and adolescents living at high altitude. Am j Human Biology 2001;13:76170.

16. Beall CM, Almasy LA, Blangero J, Williams-Nlangero S, Brittenham GM, Strohl KP et.al. Precent of oxygen saturation of arterial hemoglobin among Bolivian Aymara at 3,900 m-4000 m. Am J Phys Anthropol. 1999; 108:41-51. 